\title{
Activating Citizens to Participate in Collective Co-Production of Public Services
}

\author{
T. BOVAIRD*, G.G. VAN RYZIN**, E. LOEFFLER ${ }^{* * *}$ and S. PARRADO**** \\ *INLOGOV, University of Birmingham, Birmingham, UK \\ email:T.Bovaird@bham.ac.uk \\ ** School of Public Affairs and Administration, Rutgers University, Newark, New Jersey \\ email:Vanryzin@rutgers.edu \\ *** Governance International, Birmingham, UK \\ email: Elke.Loeffler@govint.org \\ **** Department of Political Science and Public Administration, UNED (Spanish Distance \\ Learning University), Madrid, Spain \\ email: sparrado@poli.uned.es
}

\begin{abstract}
User and community co-production of public services first became topical in the late 1970 , both in private and public sectors. Recent interest has been triggered by recognition that the outcomes for which public agencies strive rely on multiple stakeholders, particularly service users and the communities in which they live. Extra salience has been given to the potential of co-production due to fiscal pressures facing governments since 2008. However, there has been little quantitative empirical research on citizen co-production behaviours. The authors therefore undertook a large-sample survey in five European countries to fill this gap. This article examines an especially significant finding from this research - the major gulf between current levels of collective co-production and individual co-production. It explores the drivers of these large differences and examines what the social policy implications would be if, given the potential benefits, the government wishes to encourage greater collective co-production.
\end{abstract}

\section{Introduction}

User and community co-production of public services first became an important topic in the late 1970s (Ostrom and Ostrom, 1977; Whitaker, 1980; Sharp, 1980; Brudney, 1983; Brudney and England, 1983). This literature identified that user and community co-production had long been widely practised, e.g., in citizen militias, jury systems, volunteer fire fighters, etc. Particularly influential was Richard Normann (1984), who pointed out that, while in some cases service professionals 'do the service for the customer' (the 'relieving' logic), in many cases service professionals solely employ an 'enabling' logic, so the clients actually perform the service task for themselves (e.g., patients who change their diet). Over time, it has become widely accepted that services generally require inputs from both professionals and users to be fully effective. 
A second wave of interest in user and community co-production has been triggered recently by recognition that public outcomes need multiple stakeholders for their realisation, with key roles being played by service users and their communities. Consequently, co-production has come back into vogue both theoretically (Ostrom, 1996; Alford, 2002, 2009; Bovaird and Loeffler, 2012; Pestoff, 2012) and in revealing case studies (Ostrom, 1996; Alford, 1998, 2009; Joshi and Moore, 2004; Bovaird, 2007). Moreover, the fiscal pressures facing many governments since 2008 have reinforced governmental interest (OECD, 2011), with co-production becoming a common theme in European social policy, albeit through various pathways in different countries (Künzel, 2012). Fiscal pressures in turn have highlighted the role of the third sector in promoting and mediating co-production of public services (Martin, 2011; Brandsen and Pestoff, 2006; Pestoff et al., 2012; Ewart and Evers, 2012) and co-governance of public organisations (Bochel et al., 2007; Pestoff, 2012).

In spite of this growing interest, there has been little quantitative empirical research on citizen co-production. The study reported here, involving a major survey of co-production by citizens in five countries, is therefore unique. This paper examines in detail an especially significant aspect which has emerged from this study - the phenomenon of collective, as opposed to individual, coproduction. Previous research has suggested that citizens are more likely to engage in co-production of public services and social outcomes with public agencies when the relevant actions are relatively easy and can be carried out individually rather than in groups (Loeffler et al., 2008; Parrado et al., 2013). However, there are reasons to believe that much of the potential pay-off from co-production, both to the public sector and to citizens, may come from collective activities. Moreover, the increasing interest of the third sector in promoting co-production opens up opportunities for more collective action. Thus, in this study we use international survey data to compare and contrast individual and collective co-production across countries, to examine the correlates of each type of co-production and to explore the policy implications.

\section{The contested literature on individual and collective co-production}

Based on the seminal work by Ostrom and Ostrom (1977), early definitions of co-production typically referred to the contribution of resources by service users and providers to raising the quantity and/or quality of provision of a service, or in some cases their contribution to ensuring that the service was provided at all (Brudney, 1983). In this research, we use the definition from Governance International that co-production is about 'Professionals and citizens making better use of each other's assets, resources and contributions to achieve better outcomes or improved efficiency' (www.govint.org, accessed on 31 May 2014) this is in keeping with Brudney's argument but emphasises outcomes rather than simply public services. 
This definition implies that all relationships between citizens and professionals which make reciprocal use of each other's strengths can be categorised as co-production (Bovaird and Loeffler, 2010) - this includes co-commissioning (e.g., public participation in policy making, participatory budgeting), co-design (e.g., user consultative councils) and co-assessment (e.g., online satisfaction ratings for family doctors), as well as co-delivery (e.g., expert patients), the focus of many early analyses of co-production.

These different dimensions of co-production require quite different roles from service users and other citizens - and therefore different triggers and channels to mobilise citizens to play these roles. The focus in this definition on the central role of citizens in co-production excludes purely inter-organisational collaborative relationships in public services, in line with the argument in Pestoff (2012) that co-management and co-governance between organisations (e.g., between public and third sector organisations) is distinct from 'co-production' which involves the collaboration of citizens.

This definition is also valuable in emphasising the interactive nature of coproduction - stakeholders making better use of each other's resources - and thus the potential for collective action in co-production. Some authors (Ostrom, 1996) see co-production in terms primarily of individual action, whereas for others (e.g., Joshi and Moore, 2004) it implies long-term relationships (institutionalised arrangements) between state agencies and organised groups of citizens. Brudney (1983:376) accepts both possibilities, seeing co-production as active participation, beyond the normal requirements of citizenship, by either individuals or groups in the delivery of municipal services intended to raise the quality and/or amount of their provision. In her analysis, Fotaki (2011: 947) places co-production in the middle of a spectrum containing collective forms of collaborative partnerships at one end and the individualism of the market at the other end, since co-production might involve either but neither is indispensable for it.

In general, two distinct sets of criteria are found in the literature to categorise individual and collective co-production: (a) whether the outputs are collectively enjoyed and (b) whether the inputs are collectively supplied. Table 1 shows how different conceptions of co-production emerge from using these two criteria. Individually provided co-production can either be for the 'private' benefit of those directly involved in the activity, e.g., service clients, volunteers or both, or for philanthropic benefits, to be enjoyed by a wider group of people. Similarly, collectively provided co-production can bring benefits either to the private individuals directly concerned or, for altruistic or other motives, to a wider group. In practice, many co-production activities may be provided both by individuals and in collective entities and their benefits may be enjoyed both by those directly involved and by wider groups, yielding hybrid categories.

Alford (2002) distinguishes between co-production undertaken by users/clients, volunteers and members of a community. He suggests that 
TABLE 1. Conceptual approaches to 'collective co-production'

\begin{tabular}{|c|c|c|c|}
\hline & & \multicolumn{2}{|c|}{ Benefits from co-production } \\
\hline & & Individually enjoyed & Collectively enjoyed \\
\hline \multirow{6}{*}{$\begin{array}{l}\text { Inputs to co- } \\
\text { production }\end{array}$} & \multirow{2}{*}{$\begin{array}{l}\text { Individually } \\
\text { provided }\end{array}$} & A & $\mathrm{C}$ \\
\hline & & $\begin{array}{l}\text { Private individual } \\
\text { co-production } \\
\text { (Alford, 2009 - 'users/clients' } \\
\text { and 'single' volunteers) }\end{array}$ & $\begin{array}{l}\text { Philanthropic individual } \\
\text { co-production } \\
\text { (Alford, 2009 - individuals } \\
\text { acting as 'members of the } \\
\text { community') }\end{array}$ \\
\hline & \multirow[t]{4}{*}{$\begin{array}{r}\text { Collectively } \\
\text { provided }\end{array}$} & B & $\mathrm{D}$ \\
\hline & & $\begin{array}{l}\text { Private collective } \\
\text { co-production } \\
\text { (Brudney and England 1983- } \\
\text { 'group' co-production) }\end{array}$ & $\begin{array}{l}\text { Philanthropic collective } \\
\text { co-production } \\
\text { (Alford, 2009 - groups acting } \\
\text { as 'members of the } \\
\text { community') }\end{array}$ \\
\hline & & $\begin{array}{l}\text { (Alford, } 2009 \text { - 'group' } \\
\text { volunteers) }\end{array}$ & $\begin{array}{l}\text { (Thomas, } 2012-\text { 'public as } \\
\text { citizen') }\end{array}$ \\
\hline & & $\begin{array}{l}\text { (Pestoff, } 2012 \text { - 'collective } \\
\text { self-help groups' providing } \\
\text { benefits of 'individual } \\
\text { self-interest') }\end{array}$ & $\begin{array}{l}\text { (Pestoff, } 2012 \text { - 'collective } \\
\text { self-help groups' providing } \\
\text { benefits of 'collective } \\
\text { self-interest', especially } \\
\text { through collective } \\
\text { inter-action) }\end{array}$ \\
\hline
\end{tabular}

'users/clients' receive private value from the service which they co-produce within an agency - here there is no 'collective value' from the co-production activity (in Table 1, this corresponds to Box A). On the other hand, volunteers and members of the community both jointly produce and jointly 'consume' public value. Of course, service users or clients can sometimes simultaneously play this role too, when they co-produce a service. Alford sees 'volunteers', typically either in the public sector or third sector, as actively engaged in the provision of public goods or services that provide value for others, which those beneficiaries experience individually, while at the same time the volunteers may also benefit themselves (so they may be in Box A or B, depending on whether they act as individual volunteers or in groups). 'Members of a community' are generally not actively engaged in the provision of public goods or services for anyone, but are engaging in wider activities which are generally intended to benefit others (often including themselves) (so they may be in Box C or D, depending on whether they act as individuals or in groups).

Not all typologies can be so easily located within Table 1. For example, Thomas (2012a, 2012b.) in his 'citizen, customer, partner' typology posits that 'customers' seek services for private value, not for their value to the larger 
community, which would place them in Box A or B, were it not for the fact that he does not appear to place much weight on the contributions of 'customers' to the value added in these services. His category of 'public as partners' does not distinguish sharply between whether the benefits are for individual or collective benefit, and he recognises that the inputs of the 'partners' can be either individual or joint inputs (Thomas, 2012b: 798), so this category could occur in any of the four boxes. His category of 'public as citizen' does, however, clearly fit in Box D as it involves joint decision-making, essentially in the public interest.

Brudney and England (1983: 63-4), however, list individual, group and collective co-production:

- Individual co-production - either 'captured co-production', where citizens have little choice but to participate in the service as provided 'top-down' (e.g., social services clients receiving counselling support) or active, voluntary behaviours that citizens undertake for their own consumption (e.g., turning in faulty fire alarms) (Box A).

- Group co-production - voluntary, active participation by a number of citizens in groups, which may have formal or informal co-ordination mechanisms internally and between service agents and group members (e.g., neighbourhood associations where individuals join in to improve the quantity/quality of services consumed) (Box B).

- Collective co-production - where co-productive activities result in collective goods, the benefits of which may be enjoyed by the entire community (Boxes $\mathrm{C}$ and $\mathrm{D}$, depending on whether citizens act individually or together).

For the purposes of this research, we define collective co-production as the joint action of citizens to support services and achieve outcomes, while individual coproduction covers those actions not jointly undertaken. Collective co-production can arise from either individual self-interest (e.g., of service clients, volunteers or other involved citizens) or out of other motives, such as general altruism, or specific concerns for particular groups or social causes, which lead citizens to value benefits experienced collectively.

As examples of how important collective co-production is to the creation of public value, the UK has about 350,000 school governors and over 170,000 co-ordinators of Neighbourhood Watch schemes registered with the police. Collective co-production is also strong in the UK third sector, with well over 14,500 community buildings in community ownership and management and development trusts owning and managing social assets worth at least $\mathfrak{E}_{300 \mathrm{~m}}$ (Quirk, 2007).

Of course, the value of the contribution made by 'collective' co-producers cannot be estimated simply by a head count. As Bovaird and Loeffler (2010) have argued, there are 'externalities in consumption', i.e., benefits experienced by 
those indirectly affected by the consumption process of public goods. Although not given much attention in the economics literature, they include benefits to:

- those close to the user (carers, friends, volunteers, etc.) who benefit from the improved outcomes to the service user through reduction in the effort they need to make to maintain the user's quality of life, or gratification from the user's improved quality of life;

- other users, who learn how to make better use of the service from the example set by the service co-producer (e.g., the 'expert patient' who has learnt to self-administer dialysis);

- other citizens, who anticipate a need to use the service in the future ('option demand') and are reassured to see how effective it can be.

These externalities in consumption are likely to be higher in collective than in individual co-production, as there is more interaction between the co-producers involved and other citizens. Indeed, Pestoff (2012: 30) suggests that small group co-production ('collective self-help groups') can be particularly important - not only can they provide benefits of 'individual self-interest' (Box B in Table 1) and 'collective self-interest' (Box D), but they can also generate intensive collective inter-action, and are therefore rather more likely than large co-production groups to have an impact, both on the participants and on the issue which they collectively address: 'Collective action and, even more, collective interaction have the ability to transform the pursuit of self-interest into something more than the sum of individual self-interest', particularly promoting 'the development of social capital, mutualism and reciprocity' (Pestoff, 2012: 30 ).

These potential 'external' benefits suggest that collective co-production may be an appropriate target for public intervention, although Lindsay et al. (2013) note that the wider social impact is not always valued in the narrow performance management frameworks imposed by the public sector. In previous research (Loeffler et al., 2008; Parrado et al., 2013), the authors have provided evidence on the level of general user and community co-production and the attributes and correlates of those who co-produce. In this paper, we explore specifically the extent of collective co-production compared to individual co-production, the characteristics of citizens more likely to engage in collective co-production and the implications for policies aimed at promoting collective co-production.

\section{Methodology of the EU five-country study}

The empirical investigation reported here, funded by the French Presidency of the EU in 2008, provided the opportunity for what we believe is the largest ever survey of co-production behaviour and the attitudes of citizens. The five countries covered were the UK, Germany, Denmark, France and the Czech Republic, representing quite different administrative traditions, namely Anglo-Saxon, 
Prussian, Scandinavian, Napoleonic and ex-communist, and rather different social welfare regimes.

In each of the five countries, a telephone survey of the general public, designed by three of the authors, was undertaken in April and May 2008 by TNS Sofres, as one section of a longer omnibus survey. Using random dialling, the survey interviewed 4,951 adults (eighteen years of age or older), with about 1000 respondents in each country. These random samples were balanced with the population, using quotas by gender, age and region.

The survey design was informed by a series of fifteen focus groups conducted by the authors in each of the five countries, with ninety-eight participants drawn from senior representatives (in each of three selected policy areas) of central government, local public services, professional associations, national service user organisations and third sector organisations. At least one author was present in each focus group (all held in the local language, except for Denmark, where English was used), sometimes with supplementary research assistants. All sessions lasted ninety minutes, working through a common topic guide. The findings from the qualitative element of this study were reported in Loeffler et al. (2008).

The study focused on three different sub-sectors within public services: health, which is largely a personal service; community safety, which is largely regulatory; and care of the local environment, which has strong public good elements.

Co-production in these three policy areas could, of course, involve citizens in a wide range of activities, including problem identification, prevention, solving and feedback. Given resource constraints, we undertook a citizen survey rather than a user survey (where a large representative sample is more expensive to obtain). We therefore focused almost exclusively on preventative activities of citizens in all three policy areas. The questions on individual co-production explored activities which citizens can undertake personally (or can encourage others to undertake) in order to reduce need for the public services concerned (e.g., 'recycle household rubbish', 'lock doors and windows', 'tell others not to drop litter'). To explore collective co-production, respondents were asked about their participation in groups related to each of the three policy areas. In current work, we are developing a wider bank of questions which explore the wider co-commissioning, co-design, co-delivery and co-assessment dimensions of coproduction.

\section{Findings from EU five-country study}

\section{Overall levels of co-production activity}

When we asked focus groups in the five countries how important is the role of citizens in public services, the overall reaction of professional service providers was 'we don't know ... but probably very little'. However, the survey results showed a significant level of co-production by citizens in each of the three policy 


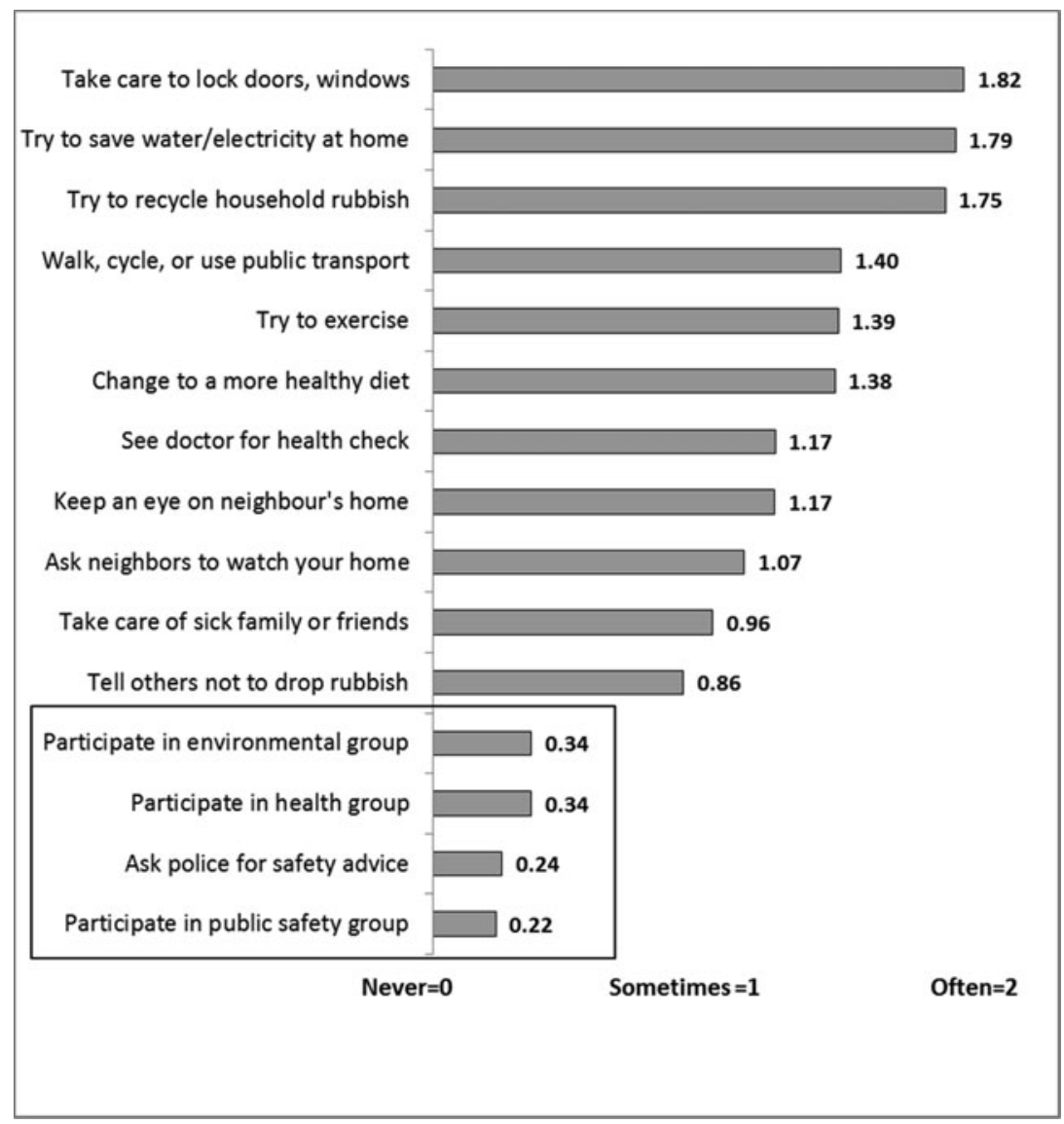

Figure 1. Which co-production activities do citizens do most often?

areas (Loeffler et al., 2008). Figure 1 shows the mean frequency ratings of coproduction activities in rank order (from highest to lowest) for all five countries combined.

The most striking pattern in Figure 1 is that citizens generally show high levels of engagement when they can undertake activities which do not need much effort or interaction with third parties, e.g., locking doors and windows in their home before going out, recycling household rubbish and saving water and electricity, all of which have means at or above 1.75 on the frequency scale (from $\mathrm{o}=$ never to $2=$ often). This is in line with the argument of Pestoff (2012: 24 ), that co-production is most likely where it is easy for citizens to become involved and where the service is seen by them as particularly salient. When it comes to the more difficult issue of making changes to personal lifestyle, there is a distinct drop - with average scores less than 1.5 on the scale for walking, cycling 


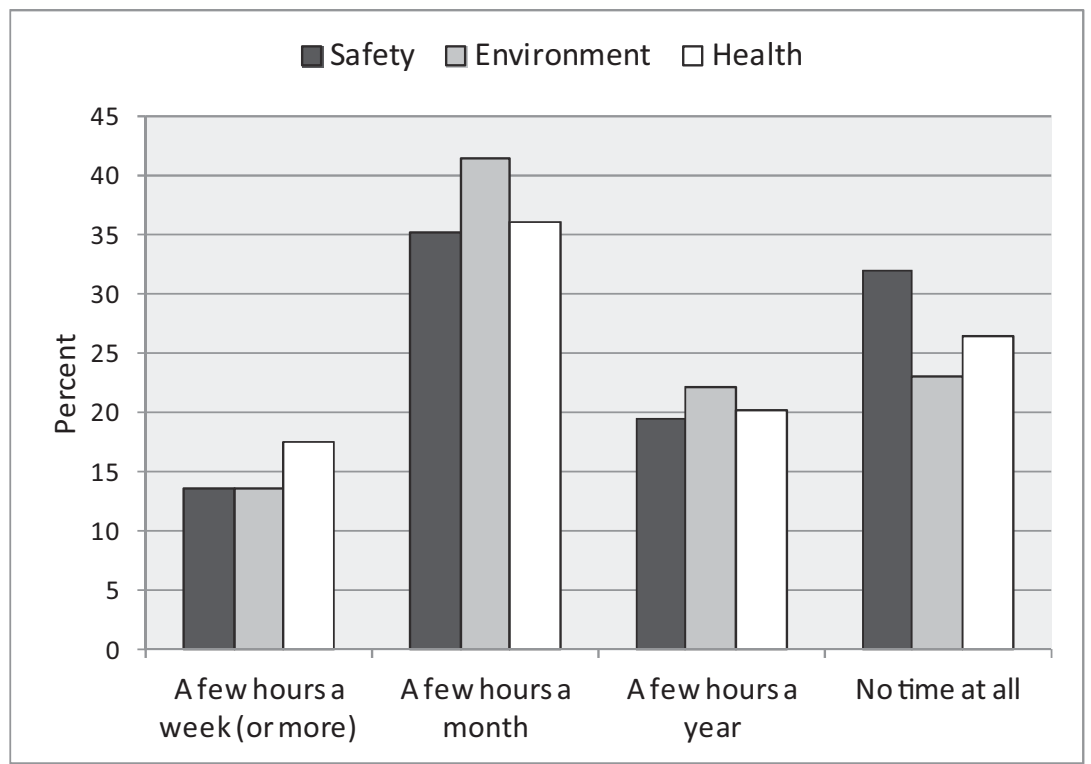

Figure 2. Time people say they are willing to volunteer in each policy area

or using public transport, changing to a more healthy diet or trying to exercise. Nevertheless, the survey also revealed a willingness of people to interact with others to resolve problems, e.g., keeping an eye on a neighbour's home, or asking a neighbour to do the same, taking care of a sick family member or friend or telling others not to drop rubbish. The average index for all of these more socially interactive activities is around 1.0, indicating that on average people do these activities at least 'sometimes', presumably because they see them as particularly salient. Activities which citizens undertook much less often involve participation in groups, whether on community safety, local environment or health. The means for these activities are all less than 0.5 , indicating that on average people only rarely engaged in these activities. The only other activity with such a low mean is asking police for safety advice.

Although people infrequently join in group activities, Figure 2 shows that nearly half of all respondents say they would be willing to spend at least a few hours a month volunteering with others (although there is less willingness to volunteer in the area of public safety, compared to local environment or health). More than one in ten said they would even spend a few hours a week or more volunteering.

\section{Levels of individual vs. collective co-production}

Using the indicators in Figures 1 and 2, we constructed separate indexes of individual and collective co-production. The collective co-production index 


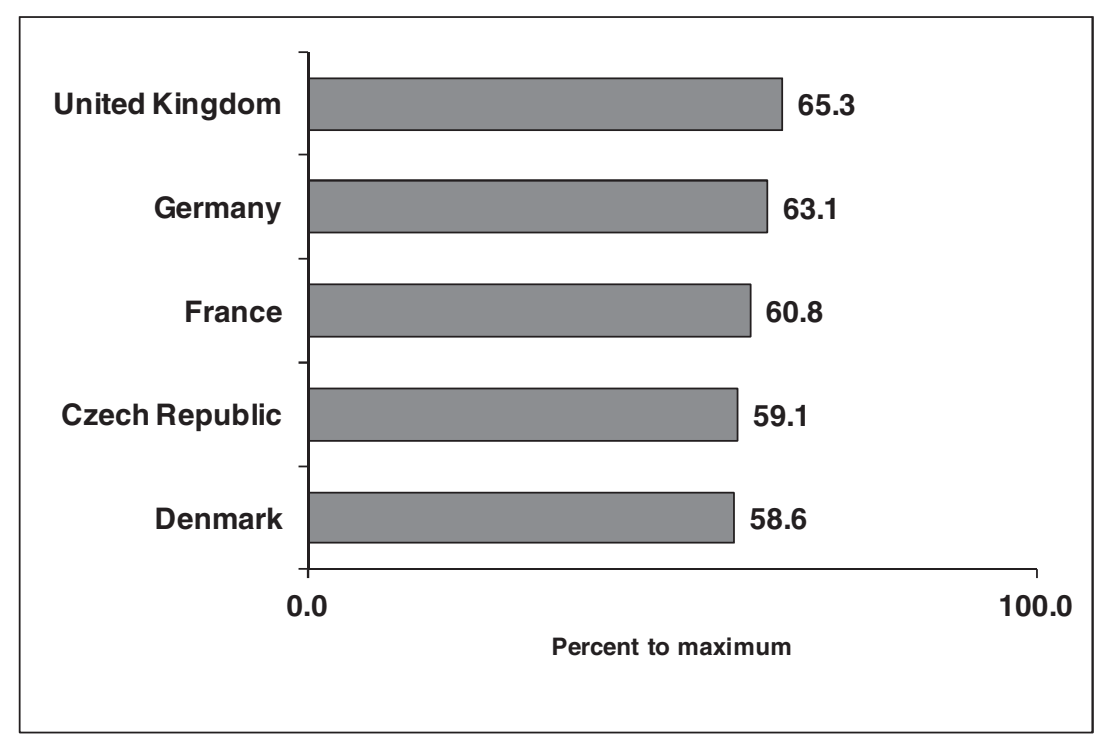

Figure 3. Individual co-production index by country

Note: Weighted results shown $(n=4951)$. The differences in means are significantly different $(\mathrm{p}<0.01)$.

was constructed using the three questions highlighted in the box in Figure 1 which deal with participation in groups, coupled with the three questions asked about willingness to volunteer with others from Figure 2. The resulting six-item collective co-production index (alpha $=0.66$ ) was then rescaled to range from o-100 (mean $=33.6, \mathrm{SD}=21.2$ ). To measure individual co-production, we used the remaining indicators from Figure 1, with four indicators from each sector (safety, environment and health). The resulting individual co-production index $($ alpha $=0.56)$ was similarly rescaled to range from o-100 (mean $=62.4, \mathrm{SD}=$ 14.7).

Figure 3 shows the mean index of individual co-production for the five countries. Overall, the levels of individual co-production are fairly high across countries, well above the midpoint of the $0-100$ scale. The UK is clearly on top, however, followed by Germany and then France. Both the Czech Republic and Denmark have lower average levels of individual co-production.

Figure 4 shows the mean index of collective co-production by country. The general level of collective co-production across the five countries is lower, well below the midpoint of the $0-100$ scale. Interestingly, in contrast to the previous results, the Czech Republic comes out on top in rankings of collective coproduction, followed by Germany and then Denmark. The UK and especially France are low in average collective co-production. 


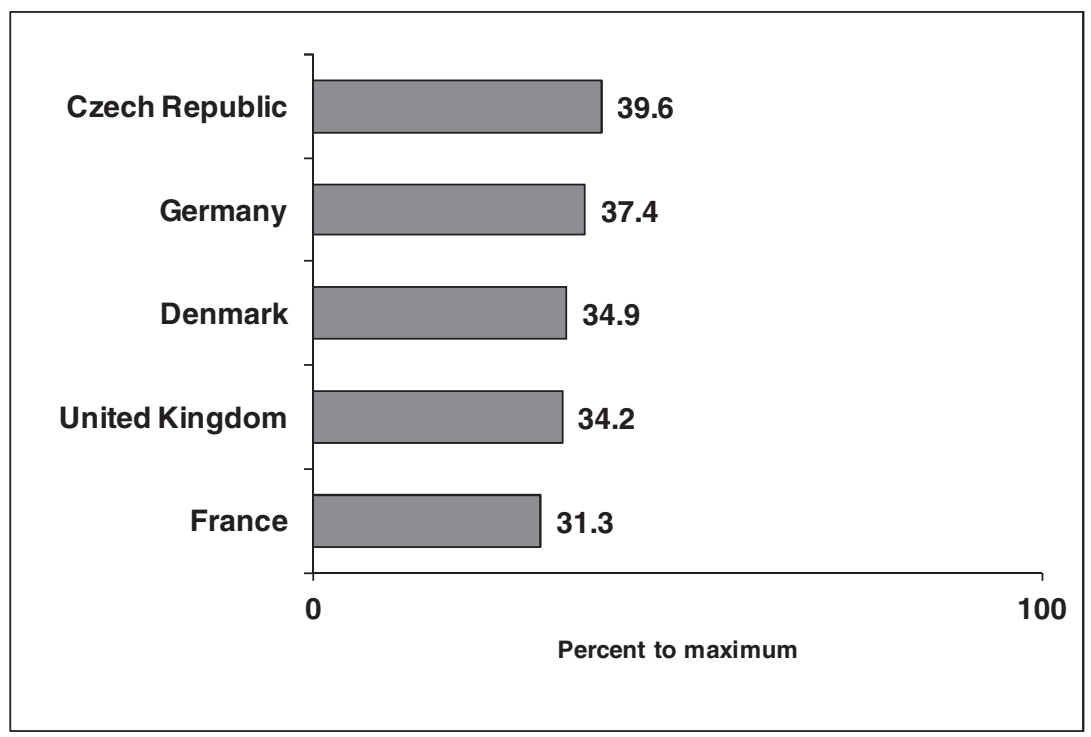

Figure 4. Collective co-production index by country

Note: Weighted results shown $(n=4951)$. The differences in means are significantly different $(\mathrm{p}<0.01)$.

\section{Key drivers of individual and collective co-production}

We used regression analysis to examine some key demographic and attitudinal variables expected to be drivers of both individual and collective co-production:

- Socio-demographic variables: age, sex, education level, labour force activity, urban/non-urban.

- Efficacy: an attitudinal variable composed of three items (alpha $=0.58)$ that asked 'how much of a difference do you believe ordinary citizens can make' with respect to improving safety, the environment and health.

- Citizens' perceptions of government: A set of scales each with three items for each of the policy areas - evaluation of government's overall performance $($ alpha $=0.52)$, satisfaction with government information $($ alpha $=0.60)$, and satisfaction with government consultation (alpha $=0.64$ ).

Thus, the regressions show the extent to which variations in the levels of individual and collective co-production are associated with variations in a person's demographic profile, along with their sense of efficacy and perceptions of government performance, information and consultation.

In Figure 5, we report results from the overall regression analysis for all five countries, showing the key drivers of individual co-production, i.e., the variables which are statistically significant predictors, arranged in descending 


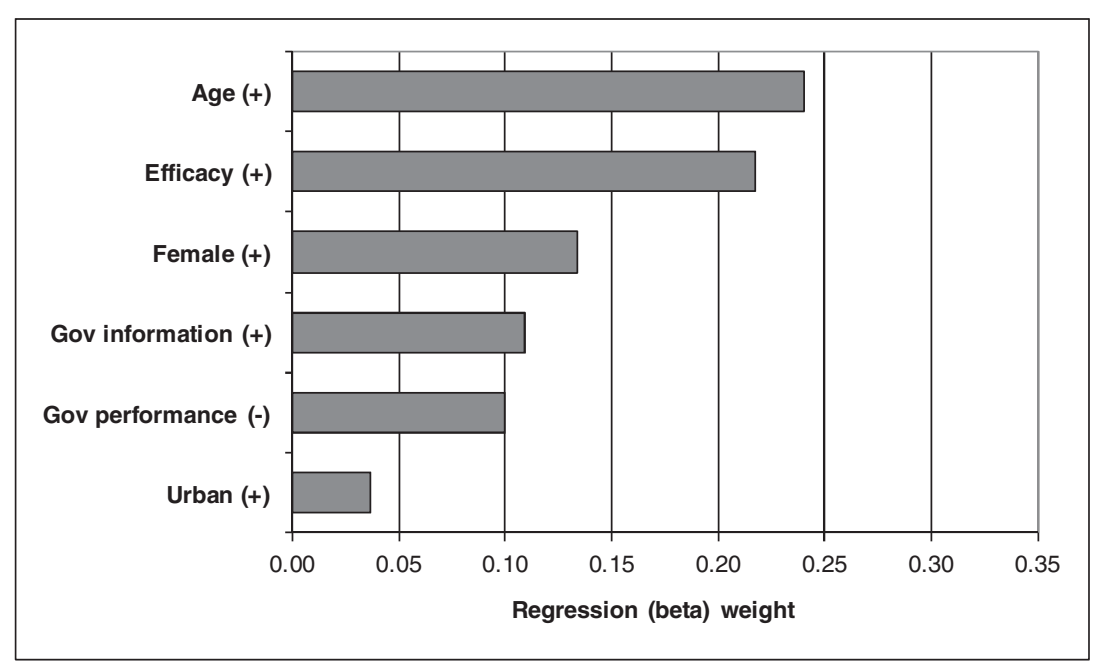

Figure 5. Key drivers (beta weights) of individual co-production

Note: Regression coefficients in rank order by beta weight; all coefficients shown are statistically significant $(\mathrm{p}<0.05)$; R-square $=0.12, n=4707$.

order of importance (measured by the standardised regression co-efficient, or beta weight).

Older citizens seem much more likely to engage in individual co-production than younger citizens. Efficacy is the next in importance, indicating that individual co-production is more likely for those respondents who believe that citizens can make a difference. Women are more likely than men to engage in individual co-production. The only other statistically significant socio-demographic factor was living in an urban area, which is a slight positive factor. Two 'attitude to government' factors were also significant respondents' satisfaction with the information they get from government was positive, while their satisfaction with government performance was negative. All of the coefficients shown are statistically significant (at $\mathrm{p}<0.05$ ); the remaining variables in the equation had non-significant effects and thus are not shown.

Figure 6 summarizes the key drivers of collective co-production, again using the combined data, presented in descending rank order by beta weight. Interestingly, the pattern of predictors is very different from the previous results. Efficacy clearly stands out as the key driver of collective co-production, meaning that those who see citizens as having the potential to make a difference are much more likely to engage in collective co-production. Older citizens, in contrast to the previous results, are less likely to engage in collective co-production. More educated citizens also have lower propensity to engage in collective coproduction. Finally, among socio-demographic factors, those inactive in the workforce are more likely to be involved in collective co-production. The 
TABLE 2. Regression analysis of individual co-production by country

\begin{tabular}{lccccc}
\hline & $\begin{array}{c}\text { Czech } \\
\text { Republic }\end{array}$ & Denmark & Germany & France & $\begin{array}{c}\text { United } \\
\text { Kingdom }\end{array}$ \\
\hline Age & $0.137^{* * *}$ & $0.198^{* * *}$ & $0.271^{* * *}$ & $0.293^{* * *}$ & $0.128^{* * *}$ \\
Female & $0.153^{* * *}$ & $0.123^{* * *}$ & $0.132^{* * *}$ & $0.126^{* * *}$ & $0.142^{* * *}$ \\
Educated & 0.043 & 0.008 & 0.016 & 0.003 & -0.010 \\
Inactive in labour force & 0.037 & 0.023 & -0.042 & 0.040 & 0.032 \\
Urban resident & $0.074^{* *}$ & 0.001 & 0.044 & $0.051^{*}$ & 0.002 \\
Sense of self efficacy & $0.120^{* * *}$ & $0.242^{* * *}$ & $0.174^{* * *}$ & $0.247^{* * *}$ & $0.250^{* * *}$ \\
Government performance & $-0.119^{* * *}$ & $-0.100^{* *}$ & $-0.096^{*}$ & -0.037 & $-0.151^{* * *}$ \\
Government information & 0.065 & $0.172^{* * *}$ & 0.131 & 0.035 & $0.161^{* *}$ \\
Government consultation & 0.061 & $-0.188^{* * *}$ & -0.084 & -0.014 & 0.011 \\
Observations (n) & 961 & 947 & 940 & 913 & 946 \\
R-squared & 0.076 & 0.123 & 0.098 & 0.181 & 0.124 \\
\hline
\end{tabular}

Note: Table shows standardised regression coefficients (beta weights); ${ }^{*} \mathrm{p}<0.10,{ }^{* *} \mathrm{p}<0.05$, ${ }^{* * *} \mathrm{p}<0.01$.

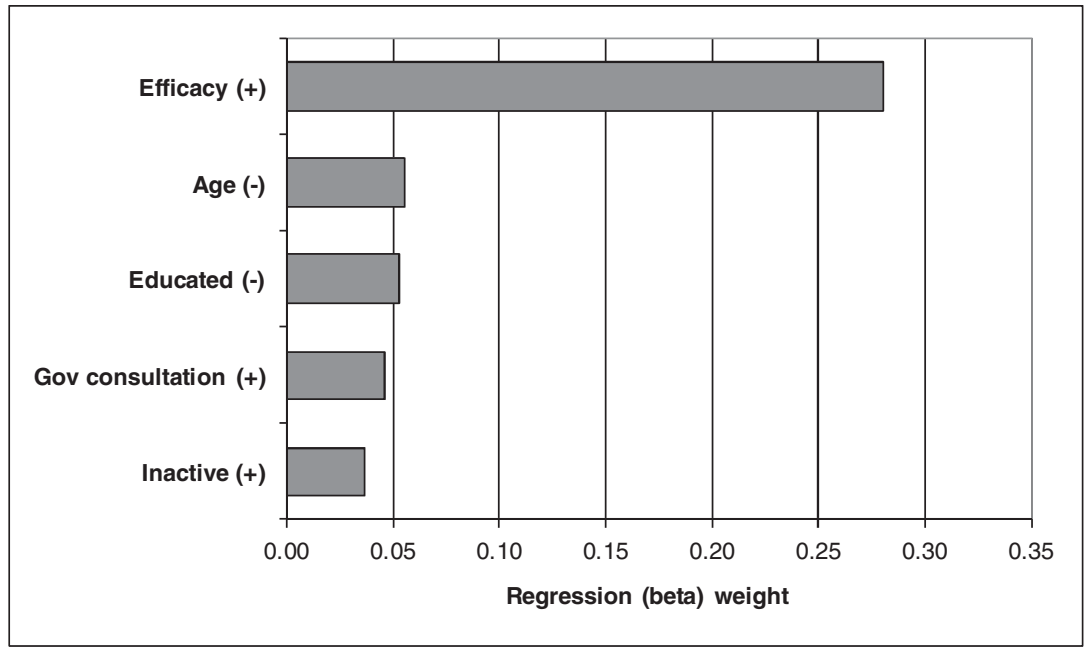

Figure 6. Key drivers (beta weights) of collective co-production

Note: Regression coefficients in rank order by beta weight; all coefficients shown are statistically significant $(\mathrm{p}<0.05)$; R-square $=0.08, n=4707$.

gender effect disappears in collective co-production. Only one 'perceptions of government' factor is significant in collective co-production - respondents' satisfaction with the extent to which government asks their opinion on issues (consultation) was positive.

To see how drivers of individual and collective co-production vary by national context, we also ran the regressions separately by country. As Table 2 shows, individual co-production has consistent positive associations with being older and female, paralleling the results of Figure 4. Also, citizens' sense of self-efficacy is a strong predictor of individual co-production in all five countries. But there 
TABLE 3. Regression analysis of collective co-production by country

\begin{tabular}{lccccc}
\hline & $\begin{array}{c}\text { Czech } \\
\text { Republic }\end{array}$ & Denmark & Germany & France & $\begin{array}{c}\text { United } \\
\text { Kingdom }\end{array}$ \\
\hline Age & $-0.144^{* * *}$ & -0.042 & -0.025 & -0.023 & $-0.113^{* * *}$ \\
Female & $0.058^{*}$ & 0.015 & 0.061 & 0.000 & 0.016 \\
Educated & 0.000 & 0.034 & $-0.041^{*}$ & $-0.086^{* * *}$ & 0.042 \\
Inactive in labor force & 0.020 & 0.059 & 0.026 & 0.036 & $0.077^{* *}$ \\
Urban resident & -0.037 & $-0.101^{* * *}$ & -0.037 & -0.043 & 0.023 \\
Sense of self efficacy & $0.168^{* * *}$ & $0.307^{* * *}$ & $0.298^{* * *}$ & $0.256^{* * *}$ & $0.311^{* * *}$ \\
Government performance & -0.064 & -0.063 & 0.062 & -0.048 & $-0.088^{*}$ \\
Government information & 0.054 & 0.028 & -0.016 & -0.011 & 0.000 \\
Government consultation & 0.063 & -0.054 & -0.006 & 0.070 & 0.064 \\
Observations (n) & 961 & 947 & 940 & 913 & 946 \\
R-squared & 0.070 & 0.110 & 0.103 & 0.073 & 0.112 \\
\hline
\end{tabular}

Note: Table shows standardised regression coefficients (beta weights); ${ }^{*} \mathrm{p}<0.10,{ }^{* *} \mathrm{p}<0.05$, *** $\mathrm{p}<0.01$.

are some differences among countries. Although government performance is negatively related to individual co-production in the Czech Republic and the UK, it is less so in Germany and not statistically significant in France. Government information is strongly and positively related to individual co-production only in Denmark and the UK. Curiously, government consultation is negatively associated with individual co-production in Denmark. Finally, urban residents are somewhat more likely to engage in co-production in the Czech Republic.

Table 3 shows the regressions by country for collective co-production. Sense of self-efficacy is clearly the dominant driver of collective co-production in all five countries. But there are some interesting differences between countries. Age is significantly negatively associated with collective co-production only in the Czech Republic and the UK. Living in an urban area is also negatively related to collective co-production in most countries, but significant only in Denmark. There is also a significant (small) negative effect of government performance on collective co-production in the UK, but not anywhere else.

\section{Discussion}

In this section, we consider the relationship of our findings to the literature. In the absence of other large-scale surveys into co-production behaviour, our comparisons have to focus on parallel findings from the literature on volunteering and civic activism, which constitute only a part of the overall spectrum of coproduction activities.

Our results on the distinctive characteristics of citizens who engage in collective rather than individual co-production show that there are significant 
differences between these types of co-production, which have not previously been picked up in the general literature on this topic.

We first consider differences in the correlation of individual and collective co-production with five socio-economic variables, then administrative and social welfare traditions and finally the perception of self-efficacy.

Age:

The finding that age is strongly positively correlated with individual coproduction but negatively correlated (if not so strongly) with collective coproduction is intriguing. To some extent, the finding on individual co-production in health may be related to the fact that some of the questions included in the index are much more likely to affect older people (e.g., 'see doctor for a health check', 'take care of sick family or friends'), but this does not apply to the other two policy fields. Putnam (2001) concluded from the literature that older people generally engage more in civic activities. However, Wilson (2012) pointed to 'a well-known peak in middle age'. Christensen and Laegreid (2005) suggest that older people trust more in government due to their more collective orientation and first-hand experience of building up the welfare state. This may well be important in individual co-production being strongly correlated with increased age, but makes it surprising that this effect does not spill over into collective co-production. Potential explanations are that the increased effort involved in collective co-production may be particularly daunting for older people, while the group nature of collective co-production may attract younger people who are interested in making more social contacts. However, this clearly needs further investigation.

\section{Gender:}

The finding that individual co-production is particularly associated with women is consistent with the conclusions of Christensen and Laegreid (2005) that women evidence higher volunteering than men. Einolf (2011: 1094) however cautions that, while most studies find that women volunteer more time than men, the size of the difference varies from study to study and from country to country and, moreover, appears to be small. Christensen and Laegreid (2005) suggest that women's higher volunteering is partly because public sector organisations employ more women and partly because the public sector has taken over some care responsibilities from women. The latter factor would imply that when women co-produce with the state, they may actually be able to reduce their commitments to those for whom they care, consistent with our findings that women's preponderance in co-production is particularly strong in health (Parrado et al., 2013). Since these care responsibilities essentially involve individual co-production, this hypothesis is corroborated by our finding that gender is not related to collective co-production. This deserves further investigation. 


\section{Urban location:}

The urban variable had a small but positive association with individual coproduction but not with collective co-production. This is consistent with the finding by Hooghe and Botterman (2012) that the urban/rural split does not have a significant impact on the intensity or the scope of participation in voluntary associations.

\section{Education:}

The education level of citizens had a small positive effect on collective co-production, but was not clearly associated with individual co-production, which therefore only partly supports studies which suggest that education level is positively related to various forms of civic participation (Egerton, 2002). However, Gesthuizen and Scheepers (2012: 75) report 'being in a higher status job positively affects volunteering and also explains why lower educated people volunteer less than the higher educated'. Consistent with our findings, they suggest that more highly educated individuals have a broader horizon, as a result of which they are more aware of collective problems and the possibility to contribute to help to solve these (which is also in line with our 'efficacy' variable). In addition, university education is strongly associated with a high level of selfefficacy (Parrado et al., 2013), which in turn is strongly associated with collective co-production, in line with our findings.

\section{Level of economic activity:}

Economic activity had no relationship with individual co-production or, outside of the UK, with collective co-production. However, in the UK being inactive in the labour force had a strong positive correlation with collective co-production behaviour. This finding contrasts with the finding of Wilson and Musick (1997) that regular employment also facilitates networks and other resources that increase capacity for volunteering and civic engagement (while also imposing constraints on free time).

\section{Overall socio-economic factors:}

While the findings demonstrate no consistent pattern in how these socioeconomic variables are linked to the overall co-production index in the three policy sectors across the five countries (Parrado et al., 2013), the distinction between individual and collective co-production has served to uncover a number of statistically significant patterns.

\section{Administrative and social welfare traditions:}

Besides exploring the association of socio-demographic characteristics with their co-production behaviour, we expected that countries with pluralistic administrative traditions (like the UK) or 'long institutionalised traditions 
for citizen involvement' like Denmark (Greve and Jesperson, 1999: 152) would have higher levels of co-production. The results show that the highest level of individual co-production is in the UK, in line with these expectations. However, unexpectedly, it turned out to be lowest in Denmark - this may be connected with a further finding that those most satisfied with public services are least likely to get involved in co-production, since Danes were the most satisfied of all five populations with conditions in all three services (Parrado et al., 2013).

The patterns are, however, very different in relation to the index of collective co-production. The Czech Republic and Germany have rather higher levels than the other three countries, with France rather lower than any of the other countries. This was unexpected and we intend to carry out further analysis on the data to explore some hypotheses as to what might underlie it. While it is possible that these differences may reflect different administrative and social welfare traditions, we intend also to explore whether it is correlated with different perceptions in each of the countries of self-efficacy, which are particularly low in the Czech Republic and Germany.

\section{Self-efficacy:}

By far the most significant finding from the study has been the role of selfefficacy. In line with the analysis of Alford (2002, 2009) about the importance of intrinsic rewards as a motivator for co-production, we expected self-efficacy of users would have an impact on service co-production. This refers to the sense acquired by an individual that they can carry out actions which entail some expected results. We have chosen to use the concept in the form of 'political selfefficacy', a longstanding concept in political science: 'the feeling that individual political action does have, or can have, an impact upon the political process ... the feeling that political and social change is possible, and that the individual citizen can play a part in bringing about this change' (Campbell and Miller, 1954: 187, quoted in Madsen 1987: 572). Research has generally suggested that self-efficacy is positively related to performance outcomes (Gist and Mitchell, 1992), such as task effort, persistence, level of interest exhibited and the level of ambition of task attempted (Bandura, 2001), so it is likely that it may affect citizens' attitudes to co-production. Moreover, Vecchione and Caprara (2009) conclude from two recent Italian surveys that self-reported political efficacy beliefs affect political participation (influenced by the 'Big Five' set of personality traits, namely openness to experience, conscientiousness, extroversion, emotional stability and agreeableness).

The question we asked in the survey was therefore: 'How much of a difference do you believe ordinary citizens can make?' with respect to improving community safety, the environment and health. While findings show that selfefficacy is strongly correlated to both individual and collective co-production (Figures 5 and 6), it is rather more strongly correlated to collective co-production, 
where it is also the dominant correlate. Our study does not provide sufficient evidence to explain fully why this is the case. However, it seems highly likely that the explanation lies in the barriers to collective co-production. As these are usually likely to be perceived as higher than in individual coproduction, it takes more motivation to attempt to overcome them. Only those with a high sense of political self-efficacy are likely to make the requisite effort.

This explanation, while still needing to be tested in more detail, is also in line with the finding reported earlier that individual co-production is strongly positively correlated with increased age, but that collective co-production is negatively (and not so strongly) correlated with age. The key may be the results reported in Parrado et al. (2013) that age is strongly negatively correlated with self-efficacy in many contexts. This strongly suggests that people are indeed more willing to co-produce as they get older, but that older people are less convinced that working with other citizens can make a difference to the quality of life outcomes about which they care. They therefore are more likely to focus on those types of co-production which they can affect personally and individually, and to make fewer efforts in collectively co-produced activities. This argument is corroborated by the finding from the UK Citizenship Survey that people aged thirty-five to forty-nine years are the most likely to feel they can influence local decisions (41 per cent), while those aged over sixty-five are the least likely (33 per cent of those aged sixty-five to seventy-four and 36 per cent of people aged seventy-five plus) (CLG, 2008: 32).

It is important to recognise that self-efficacy could be partly endogenous, in the sense that existing co-production levels in society could influence citizens' sense of self-efficacy. Alternatively, an unmeasured variable, such as trust in government or personal values, could be influencing both the sense of self-efficacy and the willingness to engage in co-production behaviour. In this study, we have found that good service performance, in the sense of a safe neighbourhood, a clean environment, and good health, seems to have a negative direct effect on co-production (Parrado et al., 2013), suggesting that co-production may depend in part on awareness of a shortfall in public performance. However, good performance may have the positive effect of enhancing citizens' selfefficacy, thereby indirectly increasing co-production. This possibility has been tested by further regressions which show that the association of higher selfefficacy with better conditions in each of the three policy areas is always positive (or close to zero) and this relationship is statistically significant in ten out of fifteen contexts (Parrado et al., 2013). The partly endogenous nature of self-efficacy naturally complicates the policy implications, to which we return later.

In summary, these findings show that we should not be too quick to pre-judge who will, and who will not, be keen to be involved in co-production. Although this 
study has identified a range of interesting and statistically significant correlates of co-production, the proportion of variation in co-production activities which is accounted for by these variables is relatively small (as shown by $\mathrm{R}^{2}$ values of 0.12 for individual co-production and 0.08 for collective co-production). Clearly, such a complex behaviour as co-production reflects many individual and contextual factors that are bound to go unmeasured in a social survey. Future research will need to explore these factors. What this means in practice is that we need to recognise the wide variation in the proportion of people from any given socio-demographic group, or with any given level of satisfaction with government performance or involvement approaches, who are likely to be active in co-producing improved public outcomes.

\section{Policy implications and further research}

This study has highlighted the major gulf between current levels of collective co-production and individual co-production, as shown by the large variations in Figure 1. If the public sector wishes to reap the potential benefits of collective co-production, then more imaginative and attractive ways will need to be found to convince a higher proportion of citizens in all these countries to re-orient their co-production activities towards more collective action.

Our research suggests that the characteristics of those who are active in collective co-production are significantly different from those who undertake individual co-production. Consequently, activating the more demanding and complex involvement in public governance represented by collective coproduction will require different mechanisms and initiatives. While this search will be demanding, the findings in Figure 2 that many citizens are actually prepared to co-produce for substantial amounts of time (much more than is currently harnessed by the public sector) suggests that the rewards from rising to this challenge could be high. Of course, these are responses by citizens about their own potential future behaviour in relation to an activity likely to be seen as socially desirable, so they may be biased upwards. This finding therefore needs corroboration from research into actual behaviour when appropriate opportunities for collective co-production are offered.

Five obvious avenues for policy development are suggested by our findings. First, collective co-production is even more closely associated with self-efficacy than is individual co-production. Identifying policies and initiatives which reinforce self-efficacy is therefore potentially attractive. There is already a long literature on this approach in the field of behaviour change. Strecher et al. (1986) concluded from a synthesis review that self-efficacy theory provides an underpinning for the notion of the 'activated patient', in direct contrast to the 'medical model' of treatment by experts. From the evidence, they suggested selfefficacy could be increased by developing awareness of specific situations where it 
is low and then rehearsing desired behaviours in these situations. Recent research in private sector services has suggested that an organisation can build up the self-efficacy of its customers by actively listening and responding, by continually innovating products and processes so as to avoid routine, and by providing ways in which customers can customise services to express their own identity (van Beuningen et al., 2011: 117).

The parallel approach to encourage collective co-production in public services would appear to suggest customised services to fit the circumstances of individual service users and then help for them to visualise and rehearse what it would be like to work more closely with others - very much the approach of the personalisation and 'person-centred planning' agenda in UK social policy in recent years (Needham and Carr, 2009; Fox et al., 2013). Furthermore, it has been suggested that those who already have a high sense of self-efficacy may be particularly effective as mentors to raise the sense of self-efficacy in those they mentor (Staples et al., 1999), indicating the power of peer support (Weaver and McCulloch, 2012), a key mechanism in collective coproduction.

Second, the corollary of the finding that older people are more likely to focus on individual co-production is that younger people are more likely to engage directly in collective co-production and (outside of France and the UK) to experience a sense of high self-efficacy. This effect may be masked for policy makers by the fact that individual co-production, the dominant form of co-production, is significantly less common among younger people. This suggests that many programmes aimed at increasing collective coproduction should aim specifically at younger age groups, and therefore would benefit from being very different in both style and content from traditional approaches.

Third, our findings on the positive effects on individual and collective co-production of government information and consultation give encouraging weight to initiatives seeking to engage citizens positively in civic affairs. Of course, the finding that individual co-production is likely to rise when government performance is perceived as poor acts as a reminder that engaged citizens sometimes co-produce out of anger or frustration as much as out of solidarity with the state. Moreover, we could not test for the effect of the intermediate variable of citizen trust in public services, which may be affected by the quality of government interaction with citizens and feed into the willingness to co-produce (Cowell et al., 2009; Parrado et al., 2013; Roberts, 2011).

Fourth, our study was confined to citizens' co-production activity in community safety, local environmental improvement and health. It seems likely that a different methodology, which focused more on service users rather than citizens generally, might have thrown up higher levels of co-production. Again, if our citizen survey had focused on other local public services, e.g., social 
care, it is possible that a rather different pattern of responses might have been observed in relation to actual co-production behaviour and willingness to engage in more co-production. We are exploring both these avenues in our current research.

Finally, the dynamics of involvement in co-production deserve more research. While our results show that many citizens are indeed involved in both kinds of co-production, we do not have data to indicate whether there is any consistent trajectory - e.g., whether people who are now active in collective coproduction started mainly through involvement in individual co-production. Such research would help to guide policy on whether to focus first on the potentially easier task of activating individual co-production or attempting from the outset the tougher task of stimulating higher levels of collective co-production, given its potentially higher pay-off.

\section{References}

Alford, J (1998), 'A public management road less travelled: clients as co-producers of public services', Australian Journal of Public Administration, 37: 4, 128-37.

Alford, J. (2002), 'Why do public-sector clients co-produce? Toward a contingency theory', Administration and Society, 34: 1, 32-56.

Alford, J. (2009), Engaging Public Sector Clients: From Service Delivery to Co-production, London: Palgrave.

Bandura, A. (2001), 'Social cognitive theory: an agentic perspective', Annual Review of Psychology, 52: 1-26.

Bochel, C., Bochel, H., Somerville, P. and Worley, C. (2007), 'Marginalised or enabled voices? "User participation" in theory and practice', Social Policy and Society, 7: 2, 20110.

Bovaird, T. (2007), 'Beyond engagement and participation - user and community coproduction of public services', Public Administration Review, 67: 5, 846-60.

Bovaird, T. and Loeffler, E. (2010), 'User and community co-production of public services and public policies through collective decision-making: role of emerging technologies', in T. Brandsen and Marc Holzer(eds.), The Future of Governance, Newark, NJ: National Center for Public Performance.

Bovaird, T. and Loeffler, E. (2012), 'From engagement to co-production: the contribution of users and communities to outcomes and public value', Voluntas, 23: 4, 1119-38.

Brandsen, T. and Pestoff, V. (2006), 'Co-production, the third sector and the delivery of public services: an introduction', Public Management Review, 8: 4, 493-501.

Brudney, J. L. (1983), 'The evaluation of coproduction programs', Policy Studies Journal, 12: 2, 376.

Brudney, J. L. and England, R. E. (1983), 'Toward a definition of the coproduction concept', Public Administration Review, 43: 59-65.

Campbell, Angus, Gurin, Gerald, and Miller, Warren E. (1954), The Voter Decides, Evanston: Row, Peterson.

Christensen, T. and Laegreid, P. (2005), 'Trust in government: the relative importance of service satisfaction, political factors, and demography', Public Performance and Management Review, 28: 4, 487-511.

CLG (2008), Communities in Control: Real People, Real Power, White Paper, Evidence Annex. London: Communities and Local Government, http://webarchive.nationalarchives. gov.uk/20120919132719/http://www.communities.gov.uk/documents/communities/pdf/ 886123.pdf (accessed 4 November 2013). 
Cowell, R., Ashworth, R., Skelcher, C., Downe, J., Bovaird, T. And Chen, A. (2009), The State of Local Democracy: The Impact of Policy Changes on Accountability and Public Confidence, Report to CLG, Cardiff: Cardiff Business School.

Egerton, M. (2002), 'Higher education and civic engagement', The British Journal of Sociology, 53: 4, 603-20.

Einolf, C. J. (2011), 'Gender differences in the correlates of volunteering and charitable giving', Nonprofit and Voluntary Sector Quarterly, 40: 6, 1092-112.

Ewert, B. and Evers, A. (2012), 'Co-production: contested meanings and challenges for user organizations', in V. Pestoff, T. Brandsen and B. Verschuere (eds.), New Public Governance, the Third Sector and Co-Production, New York: Routledge.

Fotaki, M. (2011), 'Towards developing new partnerships in public services: users as consumers, citizens and/or co-producers driving improvements in health and social care in the UK and Sweden', Public Administration, 89: 3, 933-95.

Fox, A., Fox, C. and Marsh, C. (2013), 'Could personalisation reduce re-offending? Reflections on potential lessons from British social care reform for the British criminal justice system', Journal of Social Policy, 42: 4, 721-41.

Gesthuizen, M. and Scheepers, P. (2012), 'Individual and contextual explanations educational differences in volunteering in cross-national perspective', Nonprofit and Voluntary Sector Quarterly, 41: 1, 58-81.

Gist, M. E. and Mitchell, T. R. (1992), 'Self-efficacy: a theoretical analysis of its determinants and malleability', Academy of Management Review, 17: 183-211.

Greve, C. and Jespersen, P. K. (1999), 'New Public Management and its critics: alternative roads to flexible service delivery to citizens?', in L. Rouban (ed.), Citizens and the New Governance, Amsterdam: IOS Press.

Hooghe, M. and Botterman, S. (2012), 'Urbanization, community size, and population density: is there a rural-urban divide in participation in voluntary organizations or social network formation?', Nonprofit and Voluntary Sector Quarterly, 41: 1, 120-44.

Joshi, A. and Moore, M. (2004), 'Institutionalised co-production: unorthodox public service delivery in challenging environments', The Journal of Development Studies, 40: 4, 31.

Künzel, S. (2012), 'The local dimension of active inclusion policy', Journal of European Social Policy, 22: 1, 3-16.

Lindsay, C., Osborne, S. P. and Bond, S. (2013), 'The "new public governance" and employability services in an era of crisis', Public Administration, doi: 10.1111/padm.12051.

Loeffler, E., Parrado, S., Bovaird, T. and Van Ryzin, G. (2008), "'If you want to go fast, walk alone; if you want to go far, walk together": Citizens and the co-production of public services', French Ministry of the Treasury, Public Accounts and Civil Service, on behalf of the Presidency of the EU, Paris.

Martin, G. (2011) 'The third sector, user involvement and public service reform: a case study in the co-governance of health service provision', Public Administration, 89: 3, 909-32.

Needham, C. and Carr, S. (2009), Co-Production: An Emerging Evidence Base for Adult Social Care Transformation, London: Social Care Institute for Excellence.

Normann, R. (1984), Service Management, Chichester: John Wiley.

OECD (2011), Together for Better Public Services: Partnering with Citizens and Civil Society, Paris: Organization for Economic Cooperation and Development.

Ostrom, E. (1996), 'Crossing the great divide: coproduction, synergy, and development', World Development, 24: 6, 1073-87.

Ostrom, V. and Ostrom, E. (1977), 'Public goods and public choices', in E. S. Savas (ed.), Alternatives for Delivering Public Services: Toward Improved Performance, Boulder, CO: Westview Press, pp. 7-49.

Parrado, S., van Ryzin, G., Bovaird, T. and Loeffler, E. (2013), 'Correlates of co-production: evidence from a five-nation survey of citizens', International Public Management Journal, $16: 1,1-28$. 
Pestoff, V. (2012), 'Co-production and third sector social services in Europe: some crucial conceptual issues', in V. Pestoff, T. Brandsen and B. Verschuere (eds.), New Public Governance, the Third Sector and Co-Production, New York: Routledge.

Pestoff, V., Brandsen, T. and Verschuere, B. (eds.), New Public Governance, the Third Sector and Co-Production, New York: Routledge.

Putnam, R. D. (2001), Bowling Alone: The Collapse and Revival of American Community, New York: Simon \& Schuster.

Quirk, B. (2007), Making Assets Work, London: Cabinet Office.

Roberts, J. (2011), 'Trust and early years childcare: parents' relationships with private, state and third sector providers in England', Journal of Social Policy, 40: 4, 695-715.

Sharp, E. (1980), 'Towards a new understanding of urban services and citizen participation: the co-production concept', Midwest Review of Public Administration: 14: 105-18.

Staples, D. S., Hulland, S. and Higgins, C. A. (1999), 'A self-efficacy theory explanation for the management of remote workers in virtual organizations', Organization Science, 10: 6, $758-76$.

Strecher, V. J., McEvoy, B., Becker, M. H. and Rosenstock, I. M. (1986), 'The role of self-efficacy in achieving health behaviour change', Health Education Quarterly, 13: 1, 73-91.

Thomas, J. C. (2012a), Citizen, Customer, Partner: Engaging the Public in Public Management, New York: M. E. Sharpe.

Thomas, J. C. (2012b), 'Citizen, customer, partner: rethinking the place of the public in public management', Public Administration Review, 73: 6, 786-96.

van Beuningen, J., de Ruyter, K. and Wetzels, M. (2011), 'The power of self-efficacy change during service provision: making your customers feel better about themselves pays off, Journal of Service Research, 14: 1, 108-25.

Vecchione, M. and Caprara, G. V. (2009), 'Personality determinants of political participation: the contribution of traits and self-efficacy beliefs', Personality and Individual Differences, 46: 487-92.

Weaver, B. and McCulloch, T. (2012), Co-Producing Criminal Justice: Executive Summary, Dundee: Scottish Centre for Crime and Justice Research.

Whitaker, G. (1980), 'Co-production: citizen participation in service delivery', Public Administration Review, 40: 240-6.

Wilson, J. (2012), 'Volunteerism research: a review essay', Nonprofit and Voluntary Sector Quarterly, 41: 2, 176-212.

Wilson, J. and Musick, M. A. (1997), 'Work and volunteering: the long arm of the job', Social Forces, 76: 251-71. 